\title{
A Case-Control Study of Tissue Plasminogen Activator for Acute Ischemic Stroke
}

\author{
JM Reid, SJ Phillips, GJ Gubitz, J Jarrett, C Christian, D Dai
}

\begin{abstract}
Background: Randomized trials demonstrate that intravenous tissue plasminogen activator (tPA) improves outcome in acute ischemic stroke (AIS). To assess translation of this efficacy into effectiveness in routine clinical practice we performed a casecontrol study of tPA treatment for AIS in a single hospital. Methods: 151 tPA-treated AIS patients (1996-2005) were matched 1:1 with blinding to outcome to controls from a prospective registry based on age, gender, pre-stroke Oxford handicap scale (OHS), stroke severity, and subtype. The outcomes were in-hospital death, symptomatic intracranial hemorrhage (SICH), length-of-stay (LOS), discharge OHS and long-term survival. Results: In-hospital mortality (23\% vs. $24 \%$ ) or long-term survival (median follow-up of 2 years) was not different between cases and controls ( $\mathrm{p}=0.83$ ). SICH occurred in 7.8\% (95\% CI 4.2-13.5\%) of tPA-treated patients. Median LOS was non-significantly shorter for cases (13 [7-29] vs. 16 [8-32] days, $\mathrm{p}=0.14$ ) but significantly shorter in tPA-treated vs. non-treated women (14 [7-28] vs. 20 [11-34] days, $\mathrm{p}=0.04)$. At discharge 6.6\% (95\% CI 1.1-12.0\%) more tPA-treated patients than controls had no disability (OHS $\leq 1, \mathrm{p}=0.02)$. However, there was no difference in discharge independence rates or proportion discharged home. Conclusion: We demonstrate minor improvements in early recovery after stroke with tPA but the impact is less dramatic than that reported in randomized trials. This may relate to timing of treatment and the type of patients treated.
\end{abstract}

RÉSUMÉ: Étude cas-témoins de l'activateur du plasminogène tissulaire dans le traitement de l'accident vasculaire cérébral ischémique. Contexte : Des études cliniques randomisées ont démontré que l'activateur du plasminogène tissulaire (tPA) administré par voie intraveineuse améliore l'issue dans l'accident vasculaire cérébral ischémique aigu (AVCIA). Nous avons effectué une étude cas-témoin chez des patients d'un hôpital présentant un AVCIA afin d'évaluer si l'efficacité potentielle du traitement par le tPA se traduit par une efficacité réelle en pratique clinique. Méthodes : 151 patients, ayant subi un AVCIA et ayant été traités par tPA entre 1996 et 2005, ont été appariés 1:1 quant à l'âge, au sexe, au score pré-AVC à l'Oxford Handicap Scale (OHS), à la sévérité de l'AVC et au sous-type, et en aveugle quant à l'issue, à des témoins tirés d'un registre prospectif. Les critères d'évaluation étaient le décès pendant l'hospitalisation, l'hémorragie intracrânienne symptomatique (HICS), la durée du séjour hospitalier (DSH), le score OHS au moment du congé et la survie à long terme. Résultats : Nous n'avons constaté aucune différence entre les cas et les témoins $(\mathrm{p}=0,83)$ quant à la mortalité intra-hospitalière (23\% vs $24 \%)$ et à la survie à long terme (suivi médian de 2 ans). $7,8 \%$ des patients traités par le tPA ont présenté une HICS (IC de 95\% : 4,2 à 13,5\%). La DSH médiane des cas était plus courte (13 [7-29] vs 16 [8-32] jours, p = 0,14) mais la différence n'était pas significative. Cependant elle était significative pour les femmes traitées par le tPA par rapport à celles qui n'avaient pas reçu ce traitement (14 [7-28] vs 20 [11-34] jours, p = 0,04). Au moment du congé hospitalier, les patients traités par le tPA qui n'avaient aucune invalidité étaient de 6,6\% plus nombreux (IC de 95\%: 1,1 à 12,0\%) que les témoins (OHS $\leq 1, \mathrm{p}=0,02$ ). Cependant, il n'y avait pas de différence quant au taux d'indépendance au moment du congé hospitalier ou quant à la proportion des patients qui retournaient à domicile. Conclusion : Nous démontrons qu'il existe une amélioration mineure quant à la récupération précoce après un AVCIA si on administre du tPA, mais l'impact est moins dramatique que celui qui a été rapporté dans les études randomisées. Ceci pourrait être dû au moment où le traitement est administré et au type de patients traités.

Can. J. Neurol. Sci. 2007; 34: 411-416

Intravenous tissue plasminogen activator (tPA) was licensed for acute ischemic stroke (AIS) in 1996 in the USA following the results of the National Institute of Neurological disorders and Stroke (NINDS) trial, ${ }^{1}$ then in 1999 in Canada and in 2003 in Europe. A meta-analysis of thrombolytic therapy ${ }^{2}$ for AIS showed that it is efficacious in reducing death or dependency (odds ratio $0.66,95 \%$ confidence interval [CI] 0.53 to 0.83 ) despite an increase in symptomatic intracranial hemorrhage $(\mathrm{SICH})$. The randomized evidence for the benefit of tPA within three hours of stroke onset derives from less than 1000 patients. ${ }^{3}$ Post-marketing case series with no control group demonstrate good outcomes ${ }^{4-6}$ although there are some exceptions. ${ }^{4,7}$ Without control groups however it is difficult to confirm translation of

From the Institute of Neurological Sciences (JMR), Glasgow, Scotland; Faculty of Medicine, Dalhousie University, Division of Neurology and Department of Community Health and Epidemiology (SJP, GJG, JJ, CC, DD), Queen Elizabeth II Health Sciences Centre, Halifax, Nova Scotia, Canada.

ReCEIVED February 16, 2007. ACCEPTED IN FINAL FORM MAY 27, 2007. Reprint requests to: John M. Reid, Institute of Neurological Sciences, 1345 Govan Road, Glasgow, Scotland, UK. G51 4TF 
the efficacy of tPA for AIS into effectiveness in routine clinical practice. The only case-control study of clinical practice published to date reported increased mortality with tPA use. ${ }^{7} \mathrm{We}$ describe the use of tPA to treat AIS at a single centre over a nineyear period, and report a case-control analysis of its effectiveness.

\section{Methods}

tPA-treated AIS patients were captured in a stroke registry at the Queen Elizabeth II Health Sciences Centre, a 1073-bed teaching hospital, during the nine-year interval between May 1996 and May 2005. The registry captures data prospectively on all stroke patients admitted to the stroke service since $1994^{8}$ including demographic information, pre-stroke functional status (Oxford handicap scale [OHS]), ${ }^{9}$ stroke subtype (Oxfordshire Community Stroke Project [OCSP] classification $)^{10}$ and stroke severity score $^{11}$ at presentation, vital and functional status at discharge, and discharge destination. Indications and exclusion criteria for tPA follow the guidelines of the American Stroke Association. ${ }^{12}$ Treatment decisions are made by the on-call Neurologist. All patients receiving tPA had computed tomogram (CT) brain scans before, and 24 hours after treatment. SICH was defined as a decline in neurological status in the first 36 hours after tPA that corresponded with a follow-up CT scan showing new hemorrhage consistent with the decline. National Institutes of Health Stroke Scale (NIHSS) scores were routinely recorded at presentation from March 1999. The following information was verified by chart review: medical history (previous stroke/transient ischemic attack, hypertension, diabetes mellitus, hypercholesterolemia, myocardial infarction $[\mathrm{MI}]$ or angina and ECG evidence of atrial fibrillation); laboratory results; vital signs on admission; protocol deviations; and time of stroke onset, presentation, CT scanning and tPA administration.

A control group of AIS patients from the registry were matched, with blinding to outcome, 1:1 to tPA-treated cases by gender, age ( \pm 5 years in $144 / 151, \pm 10$ years in $7 / 151)$, year of admission, pre-stroke OHS, OCSP subtype and stroke severity. Only these variables recorded at presentation were available to the two authors (JR and CC) who performed the matching process and were not involved in patient care. Seventy-four percent of controls were exactly matched by stroke severity and pre-stroke OHS. In 26\% of controls minor mismatches were permitted in either the stroke severity score (within the following categories; mild [1-4], moderate [5-7] or severe [8-10] $)^{11}$ or the pre- stroke OHS (within the categories of 0-2 [independent] or 35 [dependent]).

The outcomes were in-hospital death, time from stroke onset to death, length-of-stay (LOS), SICH rate, discharge functional status (Barthel Index $[\mathrm{BI}]^{13}$ and $\mathrm{OHS}$ ), discharge destination and long-term survival. Survival post-discharge was obtained by review of patient records and by telephone contact of patients and relatives. This work represents a compilation of several quality assurance and research studies that were approved by our local research ethics board.

\section{STATISTICAL ANALYSIS}

The data are presented as mean \pm standard deviation or median plus inter-quartile range (IQR) if the data were not normally distributed. Comparisons between groups were made using chi-square, student's t-test and 2 sample Mann-Whitney tests where appropriate. Long-term survival was analyzed using the Kaplan-Meier product limit method; cases and controls were compared using the log rank test. Significance was taken as $\mathrm{p}<0.05$.

\section{RESULTS}

During the study period, 152 AIS patients were given i.v. tPA (7\% of all AIS patients and $19 \%$ presenting <3 hours of symptom recognition). A subset of the tPA-treated patients $(n=107$, $\geq$ March 1999) had a median NIHSS score of 14 (IQR 10-19). Compared to other AIS patients from the registry, tPA-treated patients had higher rates of pre-stroke independence, male gender, atrial fibrillation and total anterior circulation stroke (TACS) OCSP subtype (Table 1), and in-hospital mortality was higher $(23 \%$ vs. $13 \%, \mathrm{p}<0.001)$, and LOS longer $(17$ [10-34] vs. 11 [7-21] days, $\mathrm{p}<0.0001)$. There was a significant negative correlation between time from stroke onset to presentation with both door to treatment and CT to treatment time (Figure 1). The median onset to treatment time of 170 (145-180) minutes did not change significantly over the nine-year period.

Protocol deviations occurred in 56/153 tPA-treated patients $(37 \%)$. The majority were time deviations $(n=35)$. Other protocol deviations included; some improvement prior to treatment $(n=8)$, blood pressure $\geq 185 / 110 \mathrm{mmHg}(\mathrm{n}=5)$, surgery in prior two weeks $(n=4), M I$ in past three months $(n=4), I N R>1.4$ or elevated partial thromboplastin time $(n=4)$, gastrointestinal or urinary tract hemorrhage in last three weeks $(n=3)$, minor or restricted deficits $(n=2)$, seizure at onset $(n=1)$. One tPA-treated patient had a small chronic subdural hematoma unrelated to clinical presentation that was initially un-noticed; there was no new hemorrhage on follow-up CT scan. One tPA-treated patient was

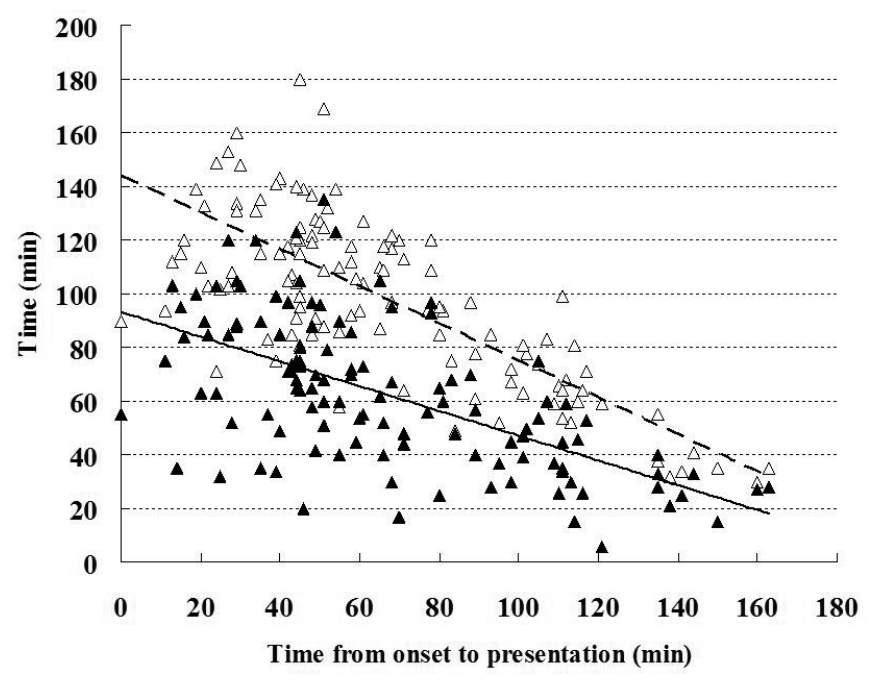

Figure 1: Time from stroke onset to presentation vs. presentation to treatment (triangles and dashed line, $p<0.0001$ ), and CT to treatment times (filled triangles and solid line, $p<0.0001$ ). 
Table 1: Characteristics of tPA-treated cases, matched controls and all other ischemic stroke patients

\begin{tabular}{|c|c|c|c|}
\hline & tPA-treated cases & Controls & All ischemic stroke \\
\hline $\mathrm{N}$ & 151 & 151 & 2034 \\
\hline Mean age & $70 \pm 12$ & $70 \pm 12$ & $71 \pm 14$ \\
\hline Male & $96(64 \%)$ & $96(64 \%)$ & $1042(51 \%)^{*}$ \\
\hline Median pre-stroke Oxford handicap scale (OHS) & $0(0-2)$ & $0(0-1)$ & $1(0-2)^{*}$ \\
\hline$\%$ Independent pre-stroke (OHS $\leq 2$ ) & $91 \%$ & $91 \%$ & $82 \%$ \\
\hline Median stroke severity score & $8(7-9)$ & $8(7-9)$ & $6(5-7) * *$ \\
\hline Total anterior circulation stroke & $78(52 \%)$ & $78(52 \%)$ & $274(13 \%)^{* *}$ \\
\hline Partial anterior circulation stroke & $56(37 \%)$ & $56(37 \%)$ & $738(36 \%)$ \\
\hline Lacunar stroke & $13(9 \%)$ & $13(9 \%)$ & $527(26 \%)^{* *}$ \\
\hline Posterior circulation stroke & $4(3 \%)$ & $4(3 \%)$ & $407(20 \%)^{* *}$ \\
\hline Median time from onset to presentation $\dagger(\mathrm{min})$ & $58(43-98)$ & $115(62-252)^{*}$ & - \\
\hline Presenting $\leq 3$ hours & $151(100 \%)$ & $105(70 \%)^{* *}$ & $654(32 \%)^{* *}$ \\
\hline Stroke on waking & 0 & $29(19 \%)^{* *}$ & $490(24 \%)^{* *}$ \\
\hline In-hospital stroke & $25(16 \%)$ & $4(3 \%)^{* *}$ & - \\
\hline Mean systolic blood pressure (mm Hg) & $151 \pm 27$ & $152 \pm 31$ & - \\
\hline Treated with iv labetalol & $9(6 \%)$ & $2(1 \%)^{*}$ & - \\
\hline Blood glucose (mmol/L) & $7.6 \pm 3.0$ & $8.4 \pm 3.4^{*}$ & - \\
\hline Atrial fibrillation & $27 \%$ & $25 \%$ & $18 \% *$ \\
\hline Previous stroke/TIA & $25 \%$ & $25 \%$ & - \\
\hline Hypertension & $62 \%$ & $62 \%$ & - \\
\hline Diabetes & $21 \%$ & $27 \%$ & - \\
\hline Smoking & $24 \%$ & $23 \%$ & - \\
\hline Dyslipidemia & $36 \%$ & $27 \%$ & - \\
\hline Ischemic heart disease & $40 \%$ & $42 \%$ & - \\
\hline Peripheral vascular disease & $7 \%$ & $7 \%$ & - \\
\hline
\end{tabular}

$\dagger$ - excluding in-hospital stroke. $* \mathrm{p}<0.05, * * \mathrm{p}<0.0001$, $\neq$ including controls. TIA -transient ischemic attack.

subsequently diagnosed as having a conversion disorder. This individual was included in the analysis of SICH and protocol deviation but excluded from other analyses.

One patient (age 19) was excluded from the case-control study as no appropriate match was available. The remaining 151 tPA-treated cases were well matched in the pre-specified variables to controls (Table 1). There were significant differences between the cases and controls in time from onset to presentation, blood glucose, proportion of strokes occurring in hospital or noted on waking, and proportion receiving acute antihypertensive therapy (Table 1). The control patients all had at least one exclusion criteria for tPA use; ${ }^{12}$ presenting $>3$ hours after symptom recognition $(n=63)$, onset to $C T$ time $>3$ hours $(n=33)$, stroke first noted on waking $(n=29)$, coagulation abnormalities $(n=28)$, stroke prior to tPA being used at our hospital (pre May 1996, $\mathrm{n}=27$ ), blood pressure $>185 / 110 \mathrm{~mm} \mathrm{Hg}$ $(n=21)$, rapidly improving $(n=8)$, head injury/stroke in last 3 months $(n=3)$, early changes on CT thought too severe $(n=3)$, other CT abnormalities $(n=2), M I$ in last 3 months $(n=2)$, gastrointestinal or urinary tract hemorrhage in last 3 weeks $(n=3)$, blood test results not available within 3 hours $(n=3)$, seizure at onset $(n=2)$, past history of intracranial hemorrhage $(n=1)$ and platelets $<100(n=1)$.

In-hospital mortality was not different between the two groups (Table 2). The SICH rate was 7.8\% (95\% CI 4.2-13.5\%) in all tPA-treated patients $(12 / 153)$ compared to $0.7 \%$ of controls (1/151). Symptomatic intracranial hemorrhage was fatal in $8 / 12(67 \%)$ tPA-treated patients. Symptomatic intracranial 
hemorrhage was not linked to protocol deviations (3/56 [5\%] vs. 9/97 [9\%], $\mathrm{p}=0.3$ ), blood pressure, age, treatment time, OCSP subtype or admission blood glucose. Protocol deviations were not associated with higher in-hospital mortality (13/56 [23\%] vs. 22/97 [23\%], $\mathrm{p}=0.99$ ).

There was no difference in median LOS comparing tPAtreated patients with controls (13 [7-29] vs 16 [8-32] days, $\mathrm{p}=0.14$, Table 2). tPA-treated women had significantly shorter LOS than their controls (14 [7-28] vs. 20 [11-34] days, $\mathrm{p}=0.04)$, with no difference between tPA-treated men and their controls (13 [8-31] vs. 14 [7-30] days, $\mathrm{p}=0.91)$. At discharge there were no significant differences in independence rate, destination, median BI or OHS (Table 2). However, 15/151 (9.9\%) of the tPA-treated patients and 5/151 (3.3\%) of the controls had no disability (OHS $\leq 1)$ at discharge (absolute difference 6.6\%, 95\% CI $1.1-12.0 \%, \mathrm{p}=0.02)$. Subgroup analysis of patients treated with tPA within two hours of symptom onset or in patients aged $<75$ did not reveal any significant benefit of tPA. After a median follow-up of two years there was no difference in survival (Figure 2).

\section{Discussion}

In this study we demonstrate that tPA-treated patients differed from the general population of hospitalized stroke patients. We did not, however, demonstrate a major benefit of tPA for AIS, although tPA-treated patients were significantly more likely to be free of disability at hospital discharge and tended to have a nonsignificantly shorter stay in hospital.

Almost twice as many men than women were treated with tPA in our study. The trend to reduced LOS seen in tPA-treated patients was noted in women but not men. This may reflect greater recovery or less neurological damage from stroke in tPAtreated women compared to men. This concurs with previous studies showing that the effect of tPA on outcome in AIS is more pronounced in women compared to $\mathrm{men}^{14}$ although this is controversial. ${ }^{15}$ The male preponderance in our study could, at least in part, explain our observations.

The lack of major benefit of tPA in this study may also be due to other factors. Firstly, patients may have been treated too late to demonstrate substantial benefit. ${ }^{3}$ Patients presenting early tend to be treated less rapidly with tPA than those who present later, as previously noted. ${ }^{16}$ Further, tPA-treated patients tended to be older than in the NINDS trial (mean age 70 vs. 68 years), ${ }^{1}$ with a higher stroke severity than in the pooled analysis of tPA trials. ${ }^{3}$ AIS patients from the NINDS trial with NHISS scores $\geq 16$ received less absolute benefit than patients with scores of 6-15. ${ }^{17}$ The high stroke severity in our tPA-treated patients is reflected in the relatively high $(23 \%)$ in-hospital mortality rate compared with $13 \%$ among all other AIS patients (Table 2). Our tPA cohort included a high proportion $(52 \%)$ of patients with TACS OCSP subtype, many of whom likely had proximal middle cerebral artery occlusions associated with low recanalization rates following i.v. tPA. ${ }^{18}$

Table 2: Outcomes of tPA-treated patients and controls

In-hospital deaths

Median time to in-hospital death (days)

Symptomatic intracranial hemorrhage

Median length of stay (days)

Median discharge Barthel Index

Median discharge Oxford handicap scale (OHS)

Independent at discharge (OHS $\leq 2)$

No disability at discharge (OHS $\leq 1)$

Discharge destination

Home

Rehabilitation unit

Nursing home

Other hospitals/services
tPA-treated

cases

151

$35(23 \%)$

\section{Matched}

controls

$\mathrm{P}$ value

$4(3-12)$

$12(7.9 \%)$

$13(7-29)$

46 (20-89)

$4(3-4)$

$28(18.5 \%)$

$15(9.9 \%)$

35

52

14

15
151

$36(24 \%)$

0.89

7 (3-14)

0.22

$1(0.7 \%)$

0.002

$16(8-32)$

0.14

47 (22-90)

0.87

$4(3-4)$

0.34

$26(17.2 \%)$

0.76

$5(3.3 \%)$

0.02

0.69

1

0.68

0.2

OHS - Oxford handicap scale 


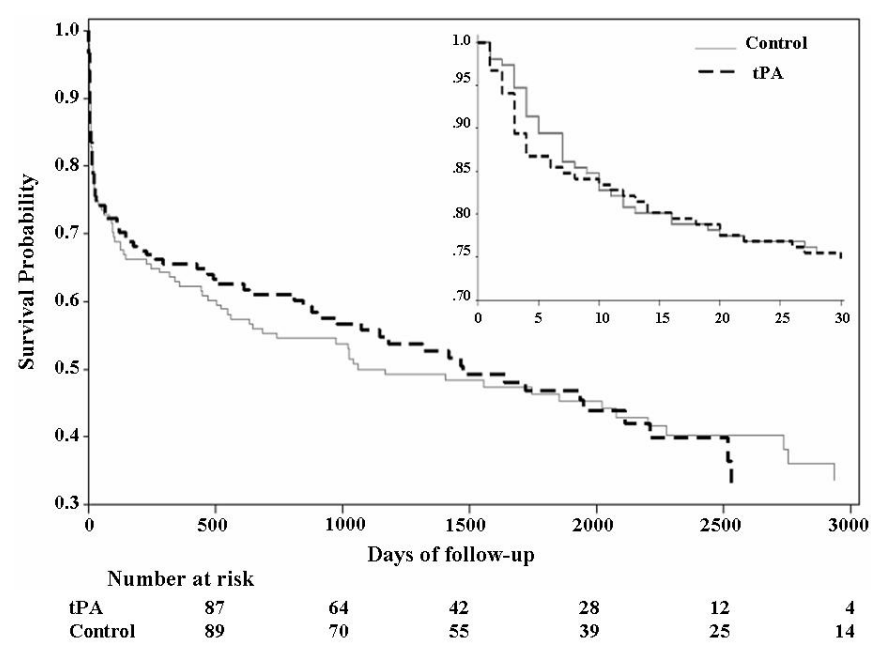

Figure 2: Kaplan-Meier analysis of survival for tPA-treated cases vs. controls, $p=0.83$. Insert - graph expanded to illustrate the first 30 days.

A meta-analysis ${ }^{4}$ of case series and a European registry ${ }^{6}$ of tPA-treated AIS patients showed rates of SICH and good outcomes that compared favorably with those observed in the treatment arm of the NINDS trial. ${ }^{1}$ However, such a comparison does not take into account differences between the study populations. Case series may be open to publication or selection bias. The recently published large European study ${ }^{6}$ excluded patients with protocol deviations or aged over 80 , likely biasing the outcome. The only previously published case-control study ${ }^{7}$ of tPA-treated AIS patients showed higher in-hospital mortality (11.7 vs. $7.4 \%)$ in tPA-treated patients. This finding was not apparent in hospitals using tPA more frequently. The authors did not report on functional outcomes. ${ }^{7}$

The case-control design of our study may have failed to eliminate possible biases or confounding factors. The cases and controls were well matched (Table 1) and differences between them, such as the higher proportion of patients with stroke noticed on waking and elevated glucose levels among controls, are associated with poor outcome. ${ }^{19,20}$ These differences would tend to favour the tPA-treated group. The fact that many control patients were admitted within three hours but did not receive tPA may mean that they had other co-morbidities that made them unsuitable candidates for thrombolysis, which would also favour the tPA group.

Other methodological aspects of this study may account for the observed lack of major benefit. We did not assess outcome at a fixed time point. Most studies of tPA in AIS report three month outcomes rather than in-hospital outcomes. ${ }^{1,2,5}$ Despite this, several significant in-hospital findings were noted in the NINDS trial; mean LOS was reduced by 1.5 days with tPA, $48 \%$ of tPAtreated patients and $36 \%$ of controls were discharged home, and the proportion of patients free of disability at 10 days was $33 \%$ in the tPA group and $18 \%$ in the control group. ${ }^{21}$ Our study had
$85 \%$ power to detect such a difference in good outcomes (i.e. free of disability) at discharge (study power calculated using nQueryAdvisor 6.0) and in fact did detect a higher proportion of patients with a discharge OHS $\leq 1$ among those treated with tPA (Table 2), concurring with the NINDS study. ${ }^{21}$ Given our study sample size we cannot exclude the play of chance in our findings due to lack of power to detect differences in other measured outcomes. In spite of the minor benefits observed with tPA, there was no difference in discharge destination.

Protocol deviations have been linked to $\mathrm{SICH}^{4,5}$ and increased mortality. ${ }^{4}$ The protocol deviation rate of $37 \%$ in this study is relatively high, ${ }^{4}$ but was not associated with increased mortality or SICH. We cannot exclude, however, that protocol deviations contributed to the lack of major benefit observed with tPA in this study. We observed no effect of tPA on mortality, SICH occurred in $7.8 \%$ (95\% CI $4.2-13.5 \%$ ) of our tPA-treated patients, in keeping with previous studies (range $2.7-15.7 \%$, average $5.2 \%) \cdot{ }^{1-5}$

We demonstrate minor improvements in early recovery after stroke with tPA but the impact is less dramatic than that reported in randomized trials. This may relate to timing of treatment and because the tPA-treated patients in our hospital were older and had more severe strokes than patients from randomized controlled trials of thrombolysis. ${ }^{1,2}$ We conclude, as others have observed, ${ }^{22}$ that further pragmatic randomized controlled trials are required to clearly define which AIS patients are most likely to benefit from tPA in routine clinical practice.

\section{ACKNOWLEDGEMENTS}

The authors thank Professor Peter Sandercock for advice regarding the manuscript.

\section{DisClOSURE}

Dr. Reid is supported by the Dalhousie University Internal Medicine Research Foundation and unrestricted educational grants from Hoffmann-LaRoche and Merck Frosst.

\section{REFERENCES}

1. The National Institute of Neurological Disorders and Stroke rt-PA Stroke Study Group. Tissue plasminogen activator for acute ischemic stroke. N Engl J Med. 1995;333(24):1581-7.

2. Wardlaw JM, del Zoppo G, Yamaguchi T. Thrombolysis for acute ischaemic stroke. The Cochrane Database of Systematic Reviews 2003, Issue 3. Art. No.: CD000213. DOI: 10.1002/14651858.CD000213.

3. Hacke W, Donnan G, Fieschi C, Kaste M, von Kummer R, Broderick JP, et al. ATLANTIS Trials Investigators; ECASS Trials Investigators; NINDS rt-PA Study Group Investigators. Association of outcome with early stroke treatment: pooled analysis of ATLANTIS, ECASS, and NINDS rt-PA stroke trials. Lancet. 2004;363(9411):768-74.

4. Graham GD. Tissue plasminogen activator for acute ischemic stroke in clinical practice: a meta-analysis of safety data. Stroke. 2003;34(12):2847-50

5. Hill MD, Buchan AM. Canadian Alteplase for Stroke Effectiveness Study (CASES) Investigators. Thrombolysis for acute ischemic stroke: results of the Canadian Alteplase for Stroke Effectiveness Study. CMAJ. 2005;172(10):1307-12.

6. Wahlgren N, Ahmed N, Davalos A, Ford GA, Grond M, Hacke W, et al. SITS-MOST investigators. Thrombolysis with alteplase for acute ischaemic stroke in the Safe Implementation of 
Thrombolysis in Stroke-Monitoring Study (SITS-MOST): an observational study. Lancet. 2007;369(9558):275-82.

7. Heuschmann PU, Berger K, Misselwitz B, Hermanek P, Leffmann C, Adelmann M, et al. German Stroke Registers Study Group; Competence Net Stroke. Frequency of thrombolytic therapy in patients with acute ischemic stroke and the risk of in-hospital mortality: the German Stroke Registers Study Group. Stroke. 2003;34(5):1106-13

8. Phillips SJ, Eskes GA, Gubitz GJ. Queen Elizabeth II Health Sciences Centre Acute Stroke Team. Description and evaluation of an acute stroke unit. CMAJ. 2002;167(6):655-60.

9. Bamford JM, Sandercock PAG, Warlow CP, Slattery J. Interobserver agreement for the assessment of handicap in stroke patients. Stroke. 1989;20(6):828.

10. Bamford J, Sandercock P, Dennis M, Burn J, Warlow C. Classification and natural history of clinically identifiable subtypes of cerebral infarction. Lancet. 1991;337(8756):1521-6.

11. Haynes RB, Mukherjee J, Sackett DL, Taylor DW, Barnett HJ, Peerless SJ. Functional status changes following medical or surgical treatment for cerebral ischemia. Results of the extracranial-intracranial bypass study. JAMA. 1987;257(15): 2043-6.

12. Adams HP Jr, Adams RJ, Brott T, del Zoppo GJ, Furlan A, Goldstein LB, et al. Stroke Council of the American Stroke Association. Guidelines for the early management of patients with ischemic stroke. A Scientific Statement from the Stroke Council of the American Stroke Association. Stroke. 2003; 34(4):1056-83

13. Mahoney FI, Barthel DW. Functional evaluation: the Barthel Index. Md State Med J. 1965;14:61-5.
14. Kent DM, Price LL, Ringleb P, Hill MD, Selker HP. Sex-based differences in response to recombinant tissue plasminogen activator in acute ischemic stroke: a pooled analysis of randomized clinical trials. Stroke. 2005;36(1):62-5.

15. Elkind MS, Prabhakaran S, Pittman J, Koroshetz W, Jacoby M, Johnston KC. GAIN Americas Investigators. Sex as a predictor of outcomes in patients treated with thrombolysis for acute stroke. Neurology. 2007 13;68(11):842-8.

16. Nadeau JO, Shi S, Fang J, Kapral MK, Richards JA, Silver FL, Hill MD. Investigators for the Registry of the Canadian Stroke Network. TPA use for stroke in the Registry of the Canadian Stroke Network. Can J Neurol Sci. 2005;32(4):433-9.

17. Ingall TJ, O'Fallon WM, Asplund K, Goldfrank LR, Hertzberg VS, Louis TA, et al. Findings from the reanalysis of the NINDS tissue plasminogen activator for acute ischemic stroke treatment trial. Stroke. 2004;35(10):2418-24.

18. del Zoppo GJ, Poeck K, Pessin MS, Wolpert SM, Furlan AJ, Ferbert A, et al. Recombinant tissue plasminogen activator in acute thrombotic and embolic stroke. Ann Neurol. 1992;32(1):78-86.

19. Jorgensen HS, Nakayama H, Christensen HR, Raaschou HO, Kampmann JP, Olsen TS. Stroke in patients with diabetes. The Copenhagen Stroke Study. Stroke. 1994;25(10):1977-84.

20. Nadeau JO, Fang J, Kapral MK, Silver FL, Hill MD. Registry of the Canadian Stroke Network. Outcome after stroke upon awakening. Can J Neurol Sci. 2005;32(2):232-6.

21. Fagan SC, Morgenstern LB, Petitta A, Ward RE, Tilley BC, Marler JR, et al. Cost-effectiveness of tissue plasminogen activator for acute ischemic stroke. NINDS rt-PA Stroke Study Group. Neurology. 1998;50(4):883-90.

22. Lindley RI, Wardlaw JM, Sandercock PA. Alteplase and ischaemic stroke: have new reviews of old data helped? Lancet Neurol. 2005;4(4):249-53. 